\title{
Development of Indian Breakfast Foods with Coconut Flour
}

\author{
Lalitha Ramaswamy ${ }^{1}$ and AR Sivagami ${ }^{2}$
}

\begin{abstract}
Coconut flour was incorporated in five Indian breakfast foods at $10 \%, 20 \%$ and $30 \%$ level by replacing the major cereal of each dish and organoleptically evaluated. Adai made with $10 \%$ incorporation had obtained the maximum scores, while those made with $20 \%$ and $30 \%$ were hard and rubbery. Uppuma made with $10 \%$ incorporation was almost equal to that of standard while the $30 \%$ incorporated one was unfit for consumption. Similarly mooli paratha made with $30 \%$ incorporation was crisp, however with $10 \%$ incorporation they were soft and acceptable. Vermicelli kichadi made with $30 \%$ incorporation was sticky, while the variation made with $10 \%$ was acceptable. Poories made with $10 \%$ incorporation were acceptable and the flavour was desirable due to the unique coconut flavour, however as the proportion of coconut flour increased the poories became crisper. Results of ANOVA show that there is a significant difference between the variations on account of coconut flour incorporation and with the standard. The fibre content of the most acceptable recipes was $4 \mathrm{~g}$ more, while the carbohydrate and fat content were less than the standard which helps in combating disease conditions like obesity and diabetes mellitus. Therefore novel foods can be formulated with coconut flour and popularised.
\end{abstract}

Key words: coconut flour, breakfast foods, protein, fibre

\footnotetext{
${ }^{1}$ Associate Professor, Dept. of Nutrition, PSG College of Arts \& Science, Coimbatore-641014, India.

${ }^{2}$ Post Graduate Student, Dept. of Nutrition, PSG College of Arts \& Science, Coimbatore-641014, India.
} 


\section{Introduction}

Breakfast is the most important meal of the day. A good breakfast provides the nutrients that people need to start their day off right. Studies show that children who eat breakfast do better in school than children who do not. Study also shows that a link between participation in the school breakfast program and improved academic performance and psychological behaviour (Pollitt, 1998).

India has a wide range of breakfast dishes varying widely by regions and between different states. The rural areas and farming communities of some South Indian states like Andhra Pradesh, Tamilnadu, Karnataka and Kerala consume rice porridge as a traditional breakfast item. In other areas kanji made with other cereals is served with various condiments such as spicy pickles or curry. Iddli and dosa the most popular and common breakfast items are served with chutney, sambhar or podi. This is usually accompanied by coffee or tea. In some Northern Indian states, parathas are served for breakfast. The accompaniments may vary depending on the likes and dislikes of individuals.

In the present study coconut flour has been incorporated in different Indian breakfast foods. The coconut flour used in the study was made from the residue after extracting coconut milk. Coconut was grated and the milk extracted and the remaining residue called sapal was soaked in hot water to remove the fat and sun dried and powdered. The fibre content of the coconut flour thus obtained was $4.2 \mathrm{~g} \%$ and protein $1.5 \mathrm{~g} \%$. This flour was incorporated in different breakfast foods.

This experiment aims to 1) formulate and evaluate recipes for different Indian breakfast foods with coconut flour and 2) calculate the nutrient composition of the recipes.

\section{Materials and Methods}

Five Indian breakfast foods namely Adai, Uppuma, Mooli Paratha, Vermicelli Kitchadi and Poori were formulated using coconut flour. In all these products the major cereal was substituted with coconut flour in different proportions.

The following is the glossary of the breakfast foods and the component that was replaced with coconut flour:

Adai A type of shallow fat fried flattened dish made with a mixture of dhals (broken pulses) and parboiled rice in the ratio of $3: 1$, soaked and ground to a thick batter.

Parboiled rice was replaced by coconut flour at $10 \%, 20 \%$, and $30 \%$ level.

Uppuma This is a boiled dish prepared with broken wheat with seasonings and onions.

Broken wheat was replaced by coconut flour at $10 \%, 20 \%$ and $30 \%$ level.

Vermicelli Kitchadi Vermicelli is an extruded product made with refined wheat flour which are long and thin. This is also a boiled dish with seasonings and vegetables.

Vermicelli was replaced by coconut flour at $10 \%, 20 \%$, and $30 \%$ level.

Pooris These are round, deep fat fried refined wheat breads.

Refined wheat flour was replaced by coconut flour at $10 \%, 20 \%$ and $30 \%$ level.

Mooli Paratha This is unleavened whole wheat bread made with fillings of grated radish and spices.

Wheat flour was replaced by coconut flour at $10 \% 20 \%$, and $30 \%$ level.

A control sample of the breakfast foods was also prepared for comparison. The recipes were organloeptically evaluated on a 5 point Hedonic scale by a panel of 10 trained judges. The nutrients were calculated using Nutritive Value of Indian Foods by Gopalan et al. (2004).

\section{Results and Discussion}

\section{Organoleptic Scores of $\boldsymbol{A d a i}$}

Adai made with 10 percent of coconut flour had got the maximum scores for taste and overall acceptability which is equal to that of 
standard (Table 1). Ten parts of coconut flour incorporation had got the maximum scores for taste because coconut flour has a mildly sweet coconut taste (Karasceviour, 2010) which also increases the overall acceptability.

Texture of 10 parts of coconut flour incorporated adai had got lower scores when compared to standard because of the fibre content of coconut flour. Adai made with 30 percent coconut flour incorporation had got least scores $(2.8 \pm 0.92)$ for texture which shows that when the proportion of coconut flour increased the texture became harder. Although adai is a dish similar to that of dosai yet it should be soft and thick as different types of dhals are added. In the present study the adai incorporated with 20 and 30 parts of coconut flour were hard and rubbery and difficult to chew.

Cow pea has been incorporated in snack products such as cookies and bread. However, it has been reported that the use of flour from raw cow pea in such formulations produces bakery products that have a raw legume flavour and hard texture. Thus there is a need to explore the use of heat treated cow pea flour to reduce the raw legume flavour and improve the texture of the end products. Micronisation of moistureconditioned seed has been shown to precook the legumes such as cow pea. The incorporation of cow pea from micronized seeds significantly increased the protein content of composite flour. Flour from micronized cow peas has been reported to contain about 24.7 percent of crude protein (Katungwe et al., 2007).

\section{Organoleptic Scores of Uppuma}

The mean organoleptic score of uppuma are given in Table 2 .

Uppuma made with 10 percent of coconut flour had got almost equal scores for all the criteria (except colour) as that of the standard. Uppuma made with 20 percent incorporated coconut flour was fairly acceptable, however 30 percent incorporated coconut flour uppuma had got very low scores and was unfit for consumption.
Composite flour includes yam, cassava, cocoyam, sweet potato; instant yam flour to mention but few attempts to improve the chemical and sensory qualities of composite especially instant yam flour has been reported by several authors (Ngoddy and Onuocha, 1983). These flours have been incorporated with wheat flour in the production of bakery goods such as cookies, breads and cakes. These flours have their properties that enhance their wide utilization which include water and oil absorption capacity, foaming capacity, foam stability. This study showed that blending sweet potato with wheat flour had significant effect on the functional properties of the flour blends. Blending sweet potato flour with wheat flour up to $20 \%$ level produced samples which can be used for production of bakery goods with improved functional properties and reduced retro-graduation, staling rate and production time (Adeleke and Odedeji, 2010).

Several studies have indicated the possibility of incorporating hulless barley, soya bean, sorghum, cow pea flour in to wheat flour at various level and the rheological and baking properties have been reported (Oftman and Gerba, 1997).

\section{Organoleptic Scores of Mooli (radish) Paratha}

As per Table 3, mooli paratha made with 10 parts of coconut flour had got the maximum scores (among the variations) and those made with 30 parts of coconut flour had got least scores in all the criteria. They were very crisp and dark brown in colour, thus confirming that they were unsuitable for consumption.

According to Chanapamokkhot and Thongngam (2007) the protein content of flour is an important component affecting flour properties and creating structure in food. In parartha the gluten content of wheat determines the structure. The addition of coconut flour in the recipes has reduced the gluten content, thereby the structure. This has affected the palatability of the paratha, resulting in an unacceptable product. 
Cord 2011, 27 (2)

Table 1. Mean Organoleptic Scores of Adai

\begin{tabular}{|l|l|c|c|c|c|c|}
\hline \multirow{2}{*}{ S.NO } & \multirow{2}{*}{ SAMPLE } & \multicolumn{5}{|c|}{ MEAN SCORE } \\
\cline { 3 - 7 } & & COLOUR & TEXTURE & FLAVOUR & TASTE & $\begin{array}{c}\text { OVERALL } \\
\text { OCCEPTABILITY }\end{array}$ \\
\hline 1. & Standard & $5 \pm 0$ & $4.7 \pm 0.483$ & $5 \pm 0$ & $5 \pm 0$ & $5 \pm 0$ \\
\hline 2. & 10 parts & $4 \pm 0$ & $4 \pm 0$ & $4.4 \pm 0.516$ & $5 \pm 0$ & $5 \pm 0$ \\
\hline 3. & 20 parts & $3.1 \pm 0.316$ & $3 \pm 0$ & $4.4 \pm 0.516$ & $4.5 \pm 0.527$ & $4.5 \pm 0.527$ \\
\hline 4. & 30 parts & $3 \pm 0$ & $2.8 \pm 0.920$ & $4 \pm 0$ & $3.9 \pm 0.316$ & $3.9 \pm 0.316$ \\
\hline
\end{tabular}

Table 2. Mean Organoleptic Scores of Uppuma

\begin{tabular}{|c|c|c|c|c|c|c|}
\hline \multirow{2}{*}{ S.NO } & \multirow{2}{*}{ SAMPLE } & \multicolumn{5}{|c|}{ MEAN SCORE } \\
\cline { 3 - 7 } & & COLOUR & TEXTURE & FLAVOUR & TASTE & $\begin{array}{c}\text { OVERALL } \\
\text { ACCEPTABILITY }\end{array}$ \\
\hline 1. & Standard & $4.6 \pm 0.516$ & $4.1 \pm 0.316$ & $4.6 \pm 0.516$ & $4.3 \pm 0.483$ & $4.3 \pm 0.483$ \\
\hline 2. & 10 parts & $3.7 \pm 0.483$ & $4.1 \pm 0.316$ & $4.3 \pm 0.483$ & $4.3 \pm 0.483$ & $4.3 \pm 0.483$ \\
\hline 3. & 20 parts & $3.8 \pm 0.422$ & $3.6 \pm 0.516$ & $4.1 \pm 0.316$ & $3.2 \pm 0.422$ & $3.5 \pm 0.527$ \\
\hline 4. & 30 parts & $3.6 \pm 0.516$ & $3.3 \pm 0.483$ & $2.9 \pm 0.316$ & $2.8 \pm 0.920$ & $2.7 \pm 0.483$ \\
\hline
\end{tabular}

Table 3. Mean Organoleptic Scores of Mooli Paratha

\begin{tabular}{|c|c|c|c|c|c|c|}
\hline \multirow{2}{*}{ S.NO } & \multirow{2}{*}{ SAMPLE } & \multicolumn{3}{|c|}{ MEAN SCORE } \\
\cline { 3 - 7 } & & COLOUR & TEXTURE & FLAVOUR & TASTE & $\begin{array}{c}\text { OVERALL } \\
\text { OCCEPTABILITY }\end{array}$ \\
\hline 1. & Standard & $4.8 \pm 0.422$ & $3.8 \pm 0.422$ & $4.3 \pm 0.483$ & $3.9 \pm 0.316$ & $4.1 \pm 0.316$ \\
\hline 2. & 10 parts & $4 \pm 0$ & $3.8 \pm 0.422$ & $4 \pm 0$ & $3.5 \pm 0.527$ & $3.9 \pm 0.316$ \\
\hline 3. & 20 parts & $3.7 \pm 0.483$ & $3.4 \pm 0.516$ & $3.4 \pm 0.516$ & $3.1 \pm 0.316$ & $3.2 \pm 0.422$ \\
\hline 4. & 30 parts & $2.5 \pm 0.527$ & $2.3 \pm 0.483$ & $3.1 \pm 0.316$ & $2.3 \pm 0.483$ & $2.4 \pm 0.516$ \\
\hline
\end{tabular}


Table 4. Mean Organoleptic Scores of Vermicelli Kitchadi

\begin{tabular}{|c|l|l|l|l|l|l|}
\hline \multirow{2}{*}{ S.NO } & \multirow{2}{*}{ SAMPLE } & \multicolumn{5}{|c|}{ MEAN SCORE } \\
\cline { 3 - 7 } & & COLOUR & TEXTURE & FLAVOUR & TASTE & $\begin{array}{c}\text { TVERALL } \\
\text { OVCEPTABILITY } \\
\text { ACCEPTA }\end{array}$ \\
\hline 1. & Standard & $5 \pm 0$ & $4.1 \pm 0.316$ & $4.8 \pm 0.412$ & $4.8 \pm 0.422$ & $4.8 \pm 0.422$ \\
\hline 2. & 10 parts & $4 \pm 0$ & $3.4 \pm 0.516$ & $4.6 \pm 0.516$ & $4 \pm 0$ & $4 \pm 0$ \\
\hline 3. & 20 parts & $3 \pm 0$ & $3.2 \pm 0.422$ & $4.6 \pm 0.516$ & $3.8 \pm 0.422$ & $3.8 \pm 0.422$ \\
\hline 4. & 30 parts & $2.5 \pm 0.527$ & $3 \pm 0$ & $4 \pm 0$ & $2.6 \pm 0.730$ & $2.6 \pm 0.730$ \\
\hline
\end{tabular}

Table 5. Mean Organoleptic Scores of Poori

\begin{tabular}{|c|c|c|c|c|c|c|}
\hline \multirow{2}{*}{ S.NO } & \multirow{2}{*}{ SAMPLE } & \multicolumn{5}{|c|}{ MEAN SCORE } \\
\hline & & COLOUR & TEXTURE & FLAVOUR & TASTE & $\begin{array}{c}\text { OVERALL } \\
\text { ACCEPTABILITY }\end{array}$ \\
\hline 1. & Standard & $5 \pm 0$ & $4 \pm 0$ & $4.6 \pm 0.516$ & $4.1 \pm 0.316$ & $4.5 \pm 0.527$ \\
\hline 2. & 10 parts & $4.5 \pm 0.527$ & $3.4 \pm 0.516$ & $4.6 \pm 0.516$ & $4.2 \pm 0.422$ & $4 \pm 0$ \\
\hline 3. & 20 parts & $4 \pm 0$ & $2.5 \pm 0.527$ & $2.9 \pm 0.316$ & $3.3 \pm 0.483$ & $2.8 \pm 0.422$ \\
\hline 4. & 30 parts & $2.8 \pm 0.920$ & $1.8 \pm 0.421$ & $1.9 \pm 0.316$ & $2.5 \pm 0.527$ & $2.5 \pm 0.527$ \\
\hline
\end{tabular}

Wheat flour and defatted soy flour blended in the ratio of $65: 20,65: 30$ and $45: 40$ were studied in respect of dough characteristics and quality of food savoury and sweet prepared from them. In fried savoury snacks the protein content increased gradually from 20.75 to 27.5 percent. When the proportion of flour was raised from 20 to 40 percent of blend corresponding rise in protein content in fried sweet snack was from 15.75 to 21.75 percent. The products were subjected to sensory evaluation by adopting preference ranking test and analysing the data using Friedman's test and Wilcoxon Mannwhitney $\mathrm{v}$ test. No significant difference was found among the samples for overall acceptability (Senthil et al., 2002).

\section{Organoleptic Scores of Vermicelli Kitchadi}

As per Table 5, vermicelli kitchadi made with 10 parts of coconut flour had got the maximum scores (among the variations) in all the criteria. Due to the addition of coconut flour the consistency of the product became creamy and sticky thus affecting the texture which eventually had a deleterious effect on taste. Shelke (2005) has noted that some fibres or proteins may absorb a lot of water and make the material too viscous to handle. Excess water can create an impact of the water activity and therefore the microbiological stability in the material and ultimately in the product could be affected. Flavour was not affected because addition of coconut flour only imparts a favourable flavour to the product.

The mineral content, essential amino acid content and selected functional properties of composite blend of maize flour in the ratio of 70:30 were flour blended with $30 \%$ bambara groundnut in addition to germination significantly improved the mineral and amino acid profile of composite blend. Sensory evaluation indicated that the bambara-maize was 
generally acceptable. The application of bambara groundnut blend to traditional foods suggest a viable option for promoting the nutritional qualities of Africa maize based traditional foods with acceptable with acceptable cooking quality (Mbata et al., 2009).

\section{Organoleptic Scores of Poori}

From Table 5, it is seen that among the variations, pooris made with 10 parts of coconut flour had got the maximum scores for all the criteria, the flavour being equal to that of standard. Poories made with 30 percent of coconut flour had obtained least scores in all the criteria. As the cooking time of 30 percent coconut flour incorporated pooris was prolonged the pooris became dark brown in colour. This prolonged cooking also made them harder making it too difficult to split in to pieces before eating.

Fibre rich foods require more chewing than other foods. High fibre foods make the stomach feel full because of the fibre's high water absorbing ability and satisfies the appetite longer than most other foods. This automatically reduces the food intake, thereby the calorie intake.

Coconut flour blended papads up to 10 percent level were acceptable and the fibre content of coconut flour blended papads was the highest and oil absorption the least (Ramaswamy and Bhuvaneswari, 2008).

ANOVA comparing mean scores of all the recipe has shown that varying levels of coconut flour significantly affected the overall acceptability of the product.

\section{Nutrient Content of the Recipes}

Selected nutrients of the most acceptable coconut flour incorporated recipes were compared with the standard.

The fibre content of all the coconut flour incorporated recipes was much higher than the standard ones (Table 6), the difference being more than 4 gram percent. The carbohydrate content of all the coconut flour incorporated recipes was lower than the standard. This will help in reducing the calorie contribution of these

recipes. Likewise the fat content of all the coconut flour incorporated recipes was lower than the standard. There was a marginal difference in the protein content of the standard and coconut incorporated ones.

\section{Figure 1. The most acceptable coconut flour incorporated recipes are shown in plates 1-5}

PLATE - 1

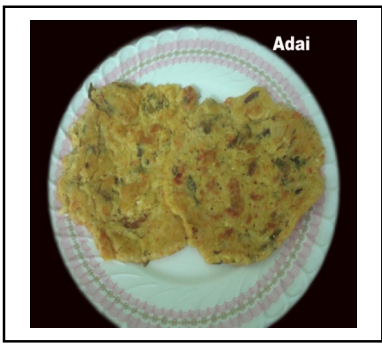

PLATE - 3

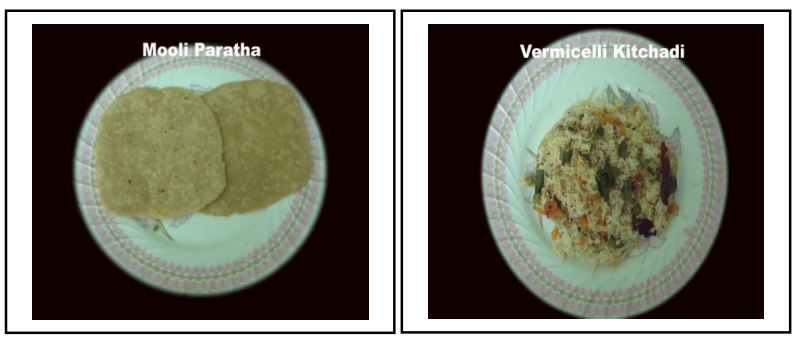

\section{PLATE - 5}

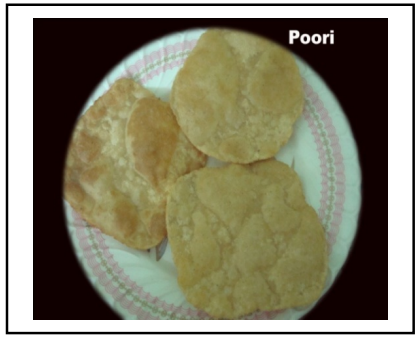

Therefore foods in which coconut flour has been incorporated will help in combating diseases like diabetes mellitus, obesity, constipation, colon cancer and cardiovascular diseases. Consumption of breakfast foods in which coconut flour has been incorporated will have a tremendous beneficial effect and help in alleviating diseases in the most organic (natural) manner. 
Table 6. Nutrient Content of Recipes

\begin{tabular}{|c|c|c|c|c|c|c|c|c|c|}
\hline S.No & Recipes & \multicolumn{8}{|c|}{ NUTRIENT CONTENT } \\
\hline & & \multicolumn{4}{|c|}{ Standard } & \multicolumn{4}{|c|}{ Most Acceptable } \\
\hline & & $\begin{array}{c}\text { CHO } \\
\text { (g) }\end{array}$ & $\begin{array}{l}\text { Protein } \\
\text { (g) }\end{array}$ & $\begin{array}{l}\text { Fat } \\
\text { (g) }\end{array}$ & $\begin{array}{c}\text { Fibre } \\
\text { (g) }\end{array}$ & $\begin{array}{c}\text { CHO } \\
\text { (g) }\end{array}$ & $\begin{array}{l}\text { Protein } \\
\text { (g) }\end{array}$ & $\begin{array}{c}\text { Fat } \\
\text { (g) }\end{array}$ & $\begin{array}{c}\text { Fibre } \\
\text { (g) }\end{array}$ \\
\hline 1 & Adai & 74.71 & 18.1 & 27.0 & 2.64 & 70 & 19.6 & 27 & 7 \\
\hline 2 & Uppuma & 62.2 & 13.0 & 12.6 & 2.6 & 58.4 & 14 & 12.4 & 6.7 \\
\hline 3 & $\begin{array}{l}\text { Mooli } \\
\text { Paratha }\end{array}$ & 71.1 & 12.2 & 21.8 & 2.05 & 67.3 & 13.2 & 21.6 & 6.2 \\
\hline 4 & $\begin{array}{l}\text { Vermicelli } \\
\text { Kitchadi }\end{array}$ & 81.7 & 10 & 16.4 & 1.1 & 77 & 11.3 & 16.3 & 5.3 \\
\hline 5 & Poori & 59.4 & 12.1 & 101.7 & 1.9 & 56 & 13.0 & 101.5 & 6.1 \\
\hline
\end{tabular}

\section{Conclusion}

From the above results, it can be concluded that coconut flour is possible to be incorporated only up to 10 percent level. Therefore it proves to be very difficult to replace standard flours with such novel flours or combination of flours especially in such common and frequently consumed Indian breakfast foods. The Indian consumer is accustomed to the appearance, texture, flavour and taste of food products made from original composition of ingredients. Such new food formulations tend to decrease the acceptability of the product. However from the point of view of the nutrient content, the recipes offer good alternatives to the original ones.

\section{Bibliography}

Adeleke R.O and Odedeji, 2010, "Functional Properties of Wheat and Sweet potato Flour blends", Pakistan Journal of Nutrition 9(6), 535-538.

Channapamokhot and Thongngam, 2007, "The chemical and Physico Chemical Properties of Sorghum Starch and Flour", Kasetsart j. (Nat. Sci), 41, Pp; 343-349.
Gopalan et al., 2002, Nutritive value of Indian foods, NIN, Hyderabad

Karasceviour, 2010, "Tropical Traditions Coconut Flour Review and Give away".

Katungwe. P, Mulwafu.A and Mwangwela A.M, 2007, "Utilisation of Flour Millled from Micronised Cow peas in maize Based Traditional Malawcan Snacks".

Mbata, T.I, Ikenebomeh and S. Ezeibe, 2009, "Evaluation of Mineral Content of Fermented Maize Flour Blended with Bambara Groundnut", African Journal of Food Science, Vol 3(4), Pp; 107-112.

Ngoddy, P.O and Onuoha. C.C, 1983, "Selected Problems in Yam Processing Symposium on Yam Biochemistry, Anambra State University, Anambra Nigeria.

Oftman, G.W and V.C Garba, 1997, "Functional Properties and Amino Acid Content of a Protein Isolate from Wing Bean Flour, Journal of Food Technology, 12, Pp; 434473.

Pollit, E. 1998, "Breakfast and Cognition an Integrative Summary", American Journal of Clinical Nutrition, 67(supp 1)804s813 s. 
Ramaswamy and Bhuvaneswari S.J, 2008, "Preparation of Blended papads using Coconut Flour and Evaluation of Selected Quality Characteristics", Indian Coconut Journal, Vol L. No.2, Pp; 10-16.

Shelke, 2005, "Healthful Flour Alternatives", Journal of the Science of Food and Agriculture, Vol, 85, Pp 2094-2104.

Senthil, R. Ravi, K. K Bhat, M. K Seethalakshmi, 2002, "Studies on the Quality of Fried Snacks Based on Blends of Wheat Flour and Soy Flour", Food quality and Preference, Pp; 267-273. 